\title{
The Status of Theme in Research Article Abstracts in Seven Dentistry Subdisciplines: A Text-Based Study of Intradisciplinary Variations and Similarities in Thematic Choices and Thematic Progression Patterns
}

\author{
Hesham Suleiman Alyousef \\ King Saud University \\ Correspondence concerning this article should be addressed to Hesham Suleiman Alyousef, Department \\ of English Language and Literature, Faculty of Arts, King Saud University, Riyadh, Saudi Arabia. \\ Email: hesham@ksu.edu.sa
}

\begin{abstract}
A research article (RA) abstract provides an overview or summary of the whole research. It is one of the most important sections in an RA since it is the first section researchers read to decide if the article is relevant to their research or not. Researchers need to know the intradisciplinary (within the same discipline) variations and similarities in the choice of Theme $^{1}$ and thematic progression (TP) patterns in RA abstracts in their discipline. Several studies have investigated variations and similarities in the use of Theme across disciplines. To the best of our knowledge, there is a lack of studies investigating intradisciplinary variations in the use of Theme in RA abstracts of dentistry subdisciplines. As epistemological differences exist between the various dentistry subdisciplines, it is pertinent to examine if there are intradisciplinary variations in the construction of Theme in the subfields of dentistry. The present study aims to investigate if there are any intradisciplinary variations and similarities in the use of Theme and TP patterns across seven dentistry subdisciplines: oral sciences, periodontics, endodontics, operative dentistry, prosthodontics, oral and maxillofacial surgery, and orthodontics. The study is framed by Halliday's systemic functional linguistics' approach to language and Daneš's model for TP patterns. The findings revealed intradisciplinary significant differences between the subfields of dentistry in terms of the use of Theme types at $\mathrm{p}<.05$ ( $\mathrm{p}$-value $=0.0294$ ), while there were no significant differences in the use of TP patterns and thematic markedness. Various interesting linguistic features characterizing the subdisciplines were found, although no significant interdisciplinary differences were found between dentistry RA abstracts and the findings reported in the literature of other disciplines. Finally, implications for novice dental researchers attempting to write an RA abstract are presented.
\end{abstract}

Keywords: Research article (RA) abstract, Theme choice, thematic progression patterns, dentistry subdiscipline, intradisciplinary and interdisciplinary variations

\section{Introduction}

Analysis of the thematic organization of discourse reveals the way texts are created and organized coherently, thereby facilitating the smooth readability of texts. The application of this analysis to the research article (RA) abstract is necessary since the findings may provide invaluable insights for writers of an RA abstract. Since the abstract summarizes the whole RA, it is the first section researchers read to decide whether or not to read the rest of the RA.

Whereas few studies investigated thematic choices and thematic progression (TP) patterns in RA abstracts of one discipline (Lorés, 2004; Nwogu \& Bloor, 1991), others conducted interdisciplinary (across disciplines) studies of variations and similarities in the thematic organization of RA abstracts across a range of disciplines

\footnotetext{
${ }_{1}$ As the word theme has other meanings (or homonyms), Theme and Rheme are capitalized in this paper to exclusively refer to Theme and Rheme parts of a clause.
} 
(Alotaibi, 2020; Ebrahimi, 2016; Ebrahimi \& Khedri, 2011; Ghadessy, 1999; Leong, 2016).The study of Theme in dentistry RA abstracts does not appear to have attracted this kind of research. Moreover, as epistemologies (or demands) are unique to each dentistry subdiscipline (or dental specialty), it is essential to investigate if there are intradisciplinary (within the same discipline) variations in the use of Theme in RA abstracts of various subfields of dentistry. For example, whereas the subdiscipline of periodontics is concerned with "oral hygiene, oral health, dental health, dental plaque, dental calculus, dental debris, dental caries, dental fluorosis, gingivitis, periodontitis, and periodontal treatment" (Shamim, 2018, p. 102), the discipline of oral and maxillofacial surgery is concerned with the treatment of cases, defects, and injuries in the head, face, neck, jaws, and the hard and soft tissues of the oral and maxillofacial region. To the best of our knowledge, there is a lack of studies investigating intradisciplinary variations in the construction of Theme in RA abstracts of dentistry subdisciplines.

The present study aims to investigate if there are any intradisciplinary variations or similarities in the use of Theme and TP patterns across seven dentistry subdisciplines. The study addressed the following research question: Are there any significant intradisciplinary variations and similarities in the choice of Theme and TP patterns in RA abstracts from seven dentistry subdisciplines: oral sciences, periodontics, endodontics, operative dentistry, prosthodontics, oral and maxillofacial surgery, and orthodontics?

\section{Theoretical Framework}

The present study is framed by Halliday's (2014) systemic functional linguistics' (SFL) approach to language and Daneš's (1974) model for TP patterns. SFL holds that language serves three main functions: experiential meanings represented by our experience of the world, interpersonal meanings represented by our use of the interactive features, and textual meanings that create cohesive and coherent texts. An analysis of the textual metafunction of a text, therefore, can reveal its organization. One of the main structural systems within the textual metafunction is Theme.

Theme is always clause-initial in the English language, it is "the element that serves as the point of departure of the message; it is that which locates and orients the clause within its context" (Halliday, 2014, p. 89). It is the first nominal, adverbial, or prepositional group or phrase that provides experiential content. Rheme, on the other hand, occurs later in a clause, it is "the part in which the Theme is developed" (ibid). For example, "half of the specimens of each group $(n=10)$ " in "half of the specimens of each group $(n=10)$ [Theme] underwent no preloading [Rheme]" (Journal of Prosthodontics, 2018) is the topical Theme and the rest of the clause is the Rheme.

The initial elements of a clause can be topical (i.e., experiential), interpersonal, and textual. Whereas the latter two elements are optional, the topical Theme is obligatory, and it is realized by a participant (nominal group), a circumstance (prepositional or adverbial phrase), or even a process (verb). For example, "17\% (7) of RCTs" in "but only 17\% (7) of RCTs [Theme] reported all 4 parameters [Rheme]" (Journal of Prosthodontics, 2018) is a topical Theme and the rest of the clause "reported all 4 parameters" is the Rheme. The two elements 'but' and 'only' are, respectively, textual and interpersonal Themes. Interpersonal Themes express a writer's opinion, while textual Themes develop grammatical and logico-semantic links within and beyond a clause (Halliday, 2014).

The second classification of thematic choices is the unmarked/marked contrast. The unmarked Theme is the typical way of starting the message of a clause, while the marked Theme is the atypical ('unusual') choice rarely employed by writers. At the clause level, the unmarked Theme in declarative statements is realized by the Subject ${ }^{2}$ (e.g. "the results [Theme] indicate that ... [Rheme]") and in marked cases by fronted complements and circumstantial adjuncts. Complements are less commonly used in academic writing than circumstantial adjuncts, and they are realized by a nominal/adjectival group and have the potential to be Subjects but they are not (e.g. "this responsibility [Theme] we accept wholly [Rheme]") (Halliday, 2014, p. 99). Circumstantial adjuncts, on the other hand, are more commonly employed, and they are realized by an adverbial or prepositional group/phrase. For example, the marked Theme "for the type of preloading" in "for the type of preloading [Theme] significant differences were observed $(\mathrm{p}=0.02 ; \mathrm{f}=5.24)$ between the Lava Plus group and

\footnotetext{
2 The subject is the constituent about which something is predicated, i.e. the grammatical subject when the verb is in active form and the object in passive.
} 
the other groups [Rheme]" (Journal of Prosthodontics, 2018) is a circumstantial adjunct realized by a prepositional phrase. One function of marked Themes is announcing a change of topic, guiding readers through the text, and showing them how to interpret the ideas being presented (Mauranen, 1996). Marked Themes then have a facilitative effect as they render the message unambiguous by setting the scene for the clause carrying the message; most writers of RA abstracts, however, minimally employ this thematic choice type due to word limit constraints.

Whereas thematic choices establish cohesion within a clause, TP patterns of Theme-Rheme can develop cohesion beyond the clause. Daneš (1974) was the first to introduce the TP model adopted by many researchers. Theme-Rheme patterns contribute to maintaining a naturally flowing text in three possible ways. One is through linear (or zig-zag/sequential) development in which the Rheme of one clause is introduced as the Theme of the subsequent clause, e.g., The sample [Theme] included 134 subjects [Rheme] ...// All subjects [Theme] had six intact maxillary anterior teeth [Rheme] (Journal of Prosthodontics-Implant Esthetic \& Reconstructive Dentistry, 2019). Authors choose to present ideas in this way to create a text that seems to flow logically. A second TP pattern, constant, is where the same Theme is reiterated (or repeated) in subsequent Themes, while Rhemes change (e.g., "A total of 44 adult patients with high, moderate and low caries risk with 516 incipient caries [Theme] took part in the study. [Rheme]// These patients [Theme] were assessed for caries with International Caries Detection and Assessment System (ICDAS) criteria [Rheme]" (Operative Dentistry, 2019). Maintaining the same entity as the Theme of more than one clause develops a topic-focused text if it is moderately employed. A third TP pattern is the split Rheme (or multiple-Theme) pattern. It is when the Rheme, mostly of a paragraph-initial clause, carries more than one idea that is then developed one by one in subsequent Themes (or clauses), as shown in Table 1.

Table 1

An example of the split Rheme pattern

\begin{tabular}{ll}
\hline \multicolumn{1}{c}{ Theme } & \multicolumn{1}{c}{ Rheme } \\
\hline The trial & $\begin{array}{l}\text { included } 68 \text { periodontal patients with dental anxiety scores of } \geqslant 13 \\
\text { who } \\
\text { whe intervention group administered progressive muscle relaxation therapy for } 20 \text { min and oral health education } \\
\text { for } 15 \text { min before periodontal treatment } \\
\text { once per week for } 4 \text { wks. }\end{array}$ \\
whe control group & was provided with oral health education only, for the same duration.
\end{tabular}

Note. Progressive muscle relaxation therapy to relieve dental anxiety: a randomized controlled trial,” by E. S. Park, H. W. Yim, and K. S. Lee, 2019, European Journal of Oral Sciences, 127(1), p. 45 (https://doi.org/10.1111/eos.12585). Copyright 2019 by Wiley.

The split Rheme pattern is considered "the most difficult for students as different pieces of information are packed or listed in the Rheme position and then picked up and used as Themes in the following clauses" (Alyousef, 2020, p. 276)

\section{Literature Review}

Whereas few studies investigated thematic choices and TP patterns in RA abstracts from one discipline (Lorés, 2004; Nwogu \& Bloor, 1991), others conducted interdisciplinary studies of variations and similarities in the thematic organization of RA abstracts across a range of disciplines (Alotaibi, 2020; Ebrahimi, 2016; Ebrahimi \& Khedri, 2011; Ghadessy, 1999; Leong, 2016).

Nwogu and Bloor (1991) investigated TP in medical RA abstracts and the findings revealed that constant and linear TP patterns were evenly employed. Lorés (2004) analyzed the rhetorical structure and thematic organization in thirty-six applied linguistics RA abstracts and the findings indicated that RA abstracts tend to combine linear and constant TP patterns, with a tendency for the Results/Discussion sections within the abstract to employ linear pattern.

Several studies investigated interdisciplinary variations in the thematic organization of RA abstracts across a range of disciplines. For example, Ghadessy (1999) conducted an interdisciplinary study of Theme 
in one hundred and fifty RA abstracts written by native and non-native students from thirty disciplines at Hong Kong Baptist University. The selection of five RA abstracts in each discipline, however, is too small to draw reliable conclusions. Moreover, the dentistry discipline was not among the thirty disciplines. The study of Theme in dentistry RA abstracts does not appear to have attracted this kind of research. Ghadessy's (1999) findings showed that unmarked topical Theme was the most frequently used type in all of the sample abstracts, with sociology having the most (100\%) and film and cinema the fewest (70.6\%). As stated in Section 2, this finding is not surprising since the unmarked Theme is the typical way of starting the message of a clause. Temporal circumstantial adverbials were more frequently used in thematic position than location adverbials. Elliptical Themes were found in most of the abstracts. In their small-scale study, Ebrahimi and Khedri (2011) investigated thematicity in ten RA abstracts from two disciplines: chemical engineering and applied linguistics. The findings revealed that the unmarked topical Theme was overused in the RA abstracts of both disciplines. Chemical engineering writers employed more interpersonal Themes (\%14) than did those of applied linguistics (\%5). Besides, the chemical engineering RA abstracts lacked instances of marked Themes. This finding could be attributed to the researchers' use of a small data set, only five RA abstracts in each discipline. In another study, Ebrahimi (2016) conducted a crossdisciplinary study of variations in the use of Theme in one hundred and twenty RA abstracts from four disciplines: applied linguistics, economics, agriculture, and applied physics. Unmarked topical Theme was also the most frequently used type, followed by the textual Theme. The marked topical Themes were more used in soft disciplines than in hard disciplines. Ebrahimi (2016, p. 108) attributes the lack of interpersonal Theme to the "argumentative nature and impersonal tone of the RA abstract genre." The findings confirm the presence of disciplinary variations in the use of Theme. Alotaibi (2020) argues that interpersonal Themes are more favored in soft disciplines than in hard disciplines. This indicates that the sciences favor a more direct style of writing. Employing Halliday's framework, Leong (2016) examined if there were any differences in the thematic organization of two hundred RA abstracts from two disciplines: sciences and the humanities. The sciences, however, did not include dentistry. The linear TP pattern was the general structure in both disciplines; the two disciplines, however, differed in the clausal distribution of topical Themes. The authors of the science RA abstracts employed more topical Themes and fewer embeddedclause topical Themes than those of the humanities. Alotaibi (2020) investigated interdisciplinary variations in the use of thematic choices in one hundred and eighty RA abstracts from six disciplines: business administration, applied linguistics, accounting, physics, chemistry, and computer science. The findings indicated that the unmarked topical Theme was the most frequently used type in all sets of RA abstracts, while the interpersonal Themes were the least frequent. Some interdisciplinary variations occurred only in textual Theme type, such as the common use of adversative conjunctions in all the disciplines. Although conjunctive adjuncts were used more than conjunctions in all six disciplines, computer science heavily employed conjunctive adjuncts (91.8\%) and Applied Linguistics employed conjunctions and conjunctive adjuncts almost equally.

The findings in the aforementioned studies indicate that a discipline's requirements (i.e. rules and conventions) influence the choice of a particular Theme type or pattern. What motivated the present study is the lack of similar investigations of intradisciplinary variations in thematic choices and TP patterns in RA abstracts from dentistry subdisciplines.

\section{Materials and Methods}

Data

The sample comprised 119 RA abstracts ( 28,847 words) of empirical studies published by dental practice scholars (Table 2) in seven dentistry subdisciplines. As the researcher was not a member of this community of practice, a practicing dentist provided support for the selection of the major dentistry subdisciplines and the selection of reputable journals with high impact. Also, since most intradisciplinary linguistic studies of RA abstracts select 12-20 abstracts in each subdiscipline, 17 RA abstracts in each subdiscipline were deemed sufficient to provide invaluable insights for dentistry academic practice. Data sampling was thus based on the idea that larger data sets would yield more reliable findings. The data selection criterion of whether the RAs were written by native or non-native authors was not taken into consideration since the RAs were published in high-ranking journals. 
Table 2

Summary of data and journals' impact factor

\begin{tabular}{|c|c|c|c|c|c|}
\hline & Dentistry Subdiscipline & Journal & Impact Factor & No. of RAs & Word Count \\
\hline 1 & Oral Sciences & European Journal of Oral Sciences & $2.220(2019)$ & 17 & 3,668 \\
\hline 2 & Periodontics & $\begin{array}{l}\text { International Journal of Periodontics \& } \\
\text { Restorative Dentistry }\end{array}$ & $1.513(2019)$ & 17 & 2,688 \\
\hline 3 & Endodontics & Journal of Endodontics & $3.118(2019)$ & 17 & 4,524 \\
\hline 4 & Operative Dentistry & Operative Dentistry & $2.213(2019)$ & 17 & 4,716 \\
\hline 5 & Prosthodontics & $\begin{array}{l}\text { Journal of Prosthodontics- Implant Esthetic \& } \\
\text { Reconstructive Dentistry }\end{array}$ & $2.187(2019)$ & 17 & 4,912 \\
\hline 6 & $\begin{array}{l}\text { Oral \& Maxillofacial } \\
\text { Surgery }\end{array}$ & British Journal of Oral \& Maxillofacial Surgery & $1.061(2019)$ & 17 & 3,448 \\
\hline \multirow[t]{2}{*}{7} & Orthodontics & European Journal of Orthodontics & $2.202(2019)$ & 17 & 4,891 \\
\hline & & & Total & 119 & 28,847 \\
\hline
\end{tabular}

The 119 RAs were published during the years 2018-2019. The abstracts were downloaded from the databases and then converted from pdf format into txt format. The abstract sections were then extracted and saved in a separate Microsoft Word file. The abstracts were carefully checked if there were any conversion errors. It should be noted that one journal covers more than one subdiscipline, the International Journal of Periodontics and Restorative Dentistry.

\section{Procedures and Instrumentation}

The unit of analysis in this study was the T-unit (Forey \& Sampson, 2017; McCabe, 1999), rather than the clause or the sentence since it has been theoretically established that the T-unit is the optimal unit for capturing TP patterns. The choice was also prompted by the fact that previous studies of thematic development in RAs selected the T-unit as their unit of analysis (Ebrahimi, 2016; Jalilifar, 2010; Leong, 2015; Leong, Toh, \& Chin, 2018; Williams, 2009).

The T-unit includes an independent clause plus one or more dependent clauses. Dependent clauses include embedded clauses, such as noun clauses and relative clauses. Young (1995) gives some examples of what a T-unit is and is not:

The following elements were counted as one T-unit: a single clause, a matrix plus subordinate clause, two or more phrases in apposition, and fragments of clauses produced by ellipsis. Co-ordinate clauses were counted as two t-units. Elements not counted as t-units include backchannel cues such as mhm and yeah, and discourse boundary markers such as okay, thanks or good. False starts were integrated into the following t-unit (Young, 1995, p. 38).

Fries (1995, p. 318) defines a T-unit as "a clause complex which contains one main independent clause together with all the hypotactic clauses which are dependent on it.” Thus, there will be two T-units if a sentence includes two independent clauses.

The steps in analyzing the data were as follows. T-units were calculated using the Web-based L2 Syntactic Complexity Analyzer (Ai \& Lu, 2013; Lu, 2010, 2011; Lu \& Ai, 2015), Single Mode. Each independent clause in the RAs was identified and recorded and the Theme of each independent clause was classified. Each topical Theme was coded as marked or unmarked. Next, the TP patterns were identified. All of the features identified in the dentistry RA abstracts were reported both qualitatively and quantitatively. Since the RA abstracts for dentistry subdiscipline had different lengths in relation to their effect on the frequency count of the T-units, the frequency counts for Themes based on T-units can be inflated by RA text length. To account for the differing number of T-units, the total number of occurrences of a Theme type/TP pattern in a given subdiscipline was divided by the total number of occurrences of all Theme types/TP patterns in 
each subdiscipline and then the result was multiplied by 100. This in turn will facilitate comparability across the seven dentistry subdisciplines regarding variations or similarities in the choice of Theme and TP patterns. Furthermore, a chi-square test was run, employing Preacher's online chi-square Test Calculator ${ }^{3}$ to investigate if there were significant differences between the frequencies of occurrence of the three thematic aspects (Theme types, thematic markedness, and TP patterns) in the seven dentistry subdisciplines.

\section{Recognition of Theme-Rheme and TP Patterns: Delimitations}

The annotation of Theme-Rheme is not always straightforward as there are issues in the delimitation of Theme, such as the cases of marked and multiple topical Themes in clause complexes: What counts as a Theme? Where does Theme stop and Rheme begin? Halliday's (2014) and other scholars' (Hasan \& Fries, 1995; McGregor, 1992) positions in this regard were adopted since such analysis renders the method of development of the message clearer as the clause identifies the point of departure.

The identification of a Theme depends on the position of the dependent clause in the complex T-unit. If it occurs initially, the entire clause is considered the Theme; if the independent clause occurs initially, the grammatical subject is the Theme. For example, the circumstantial prepositional clause in the following sentence is the Theme of the clause complex:

\begin{tabular}{ll}
\hline After 6 months, & $\begin{array}{l}\text { all groups showed similar total MMP activity, } \\
\text { dry mass loss, and HYP release, // (European Journal of Oral Sciences, 2019, 127, 1-9) }\end{array}$ \\
Theme & Rheme \\
\hline
\end{tabular}

Since the clause "after 6 months" has the ideational function of temporal circumstance, it is a marked topical Theme. A Theme is realized here by the elements preceding the grammatical subject. According to Hasan and Fries (1995, p. xxxvi), "everything up to and including the element Subject is Theme so long as there is no marked Topical Theme." Thus, the Subject is excluded in the case of marked topical Theme since it has a Mood function other than Subject.

Elliptical and structural-topical Themes, such as 'that' in relative clauses and 'which/who,' conflate with the Subject. In the case of empty grammatical subjects ('it' and existential clauses), the finite (verb) is regarded as the topical Theme. This contradicts the Hallidayan approach, which marks empty subjects as the Theme. Leong (2004, pp. 202-203) argues that since empty subjects such as "there" and "it" do not carry experiential content, it would be "unacceptable, both theoretically and intuitively, since this amounts to saying that the rheme develops nothing."

Following Thompson (2004), anticipatory "it" and the projecting clause are treated as thematized comments (or interpersonal projections) of a writer's claims. The dummy "it" (or place-holder) and the projecting clause "it is very important" in "it is very important to prevent tooth decay from eroding" are annotated as the Theme since the method of development will be obscured if only "it" is selected.

\section{Results and Discussion}

This section attempts to investigate and discuss if there are any significant intradisciplinary variations or similarities in the choice of Theme and TP patterns in the RA abstracts from seven dentistry subdisciplines: oral sciences, periodontics, endodontics, operative dentistry, prosthodontics, oral and maxillofacial surgery, and orthodontics. Table 3 shows the frequencies and percentages and the chi-square distribution of the three thematic aspects (Theme types, thematic markedness, and TP patterns) in the seven dentistry subdisciplines at both local and global levels.

\footnotetext{
3 Preacher, K. J. (2001, April). Calculation for the chi-square test: An interactive calculation tool for chi-square tests of goodness of fit and independence [Computer software]. http://www.quantpsy.org/chisq/chisq.htm.
} 


\section{HESHAM SULEIMAN ALYOUSEF}

Table 3

The frequency and percentage of three thematic aspects in the seven subdisciplines

\begin{tabular}{|c|c|c|c|c|c|c|c|c|c|c|c|c|c|c|c|c|c|}
\hline & & \multicolumn{2}{|c|}{$\begin{array}{c}\text { Oral } \\
\text { Sciences }\end{array}$} & \multicolumn{2}{|c|}{$\begin{array}{r}\text { Perio- } \\
\text { dontics }\end{array}$} & \multicolumn{2}{|c|}{$\begin{array}{c}\text { Endo- } \\
\text { dontics }\end{array}$} & \multicolumn{2}{|c|}{$\begin{array}{l}\text { Operative } \\
\text { Dentistry }\end{array}$} & \multicolumn{2}{|c|}{$\begin{array}{l}\text { Prostho- } \\
\text { dontics }\end{array}$} & \multicolumn{2}{|c|}{$\begin{array}{c}\text { Oral \& } \\
\text { Maxillofacial } \\
\text { Surgery }\end{array}$} & \multicolumn{2}{|c|}{$\begin{array}{l}\text { Ortho- } \\
\text { dontics }\end{array}$} & \multirow[t]{2}{*}{ 当站 } & \multirow[t]{2}{*}{ 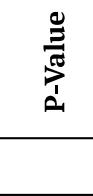 } \\
\hline & & Freq & $\%$ & Freq & $\%$ & Freq & $\%$ & Freq & $\%$ & Freq & $\%$ & Freq & $\%$ & Freq & $\%$ & & \\
\hline & Words & 3668 & & 2688 & & 4524 & & 4716 & & 4912 & & 3448 & & 4891 & & & \\
\hline & T-Units & 194 & 100 & 132 & 100 & 230 & 100 & 229 & 100 & 242 & 100 & 176 & 100 & 263 & 100 & & \\
\hline \multirow{4}{*}{ 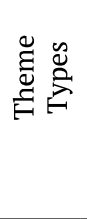 } & Topical & 194 & 85.46 & 132 & 86.84 & 230 & 90.55 & 229 & 89.11 & 242 & 87.68 & 176 & 87.56 & 263 & 93.59 & & \\
\hline & Textual & 33 & 14.54 & 19 & 12.50 & 24 & 9.45 & 28 & 10.89 & 30 & 10.87 & 24 & 11.94 & 15 & 5.34 & & \\
\hline & Interpers. & 0 & 0.00 & 1 & .66 & 0 & 0.00 & 0 & 0.00 & 4 & 1.45 & 1 & .50 & 3 & 1.07 & & \\
\hline & & 227 & 100 & 152 & 100 & 254 & 100 & 257 & 100 & 276 & 100 & 201 & 100 & 281 & 100 & 22.806 & 0.0294 \\
\hline \multirow{3}{*}{ 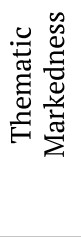 } & $\begin{array}{l}\text { Un- } \\
\text { marked }\end{array}$ & 179 & 92.27 & 113 & 85.60 & 204 & 88.69 & 195 & 85.15 & 216 & 89.26 & 154 & 87.50 & 244 & 92.78 & & \\
\hline & Marked & 15 & 7.73 & 19 & 14.40 & 26 & 11.31 & 34 & 14.85 & 26 & 10.74 & 22 & 12.50 & 19 & 7.22 & & \\
\hline & & 194 & 100 & 132 & 100 & 230 & 100 & 229 & 100 & 242 & 100 & 176 & 100 & 263 & 100 & 11.419 & 0.0762 \\
\hline \multirow{4}{*}{ 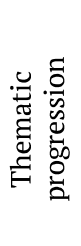 } & Linear & 33 & 63.46 & 22 & 64.71 & 31 & 50 & 33 & 57.89 & 26 & 45.62 & 18 & 52.94 & 15 & 45.46 & & \\
\hline & Constant & 16 & 30.77 & 12 & 35.29 & 30 & 48.39 & 22 & 38.60 & 28 & 49.12 & 14 & 41.18 & 16 & 48.48 & & \\
\hline & $\begin{array}{l}\text { Split } \\
\text { Rheme }\end{array}$ & 3 & 5.77 & 0 & 0.00 & 1 & 1.61 & 2 & 3.51 & 3 & 5.26 & 2 & 5.88 & 2 & 6.06 & & \\
\hline & & 52 & 100 & 34 & 100 & 62 & 100 & 57 & 100 & 57 & 100 & 34 & 100 & 33 & 100 & 10.436 & 0.5777 \\
\hline
\end{tabular}

A detailed presentation and discussion of the findings is presented below in terms of local and global levels organization of Theme in the seven dentistry subdisciplines.

\section{Local Organization}

The chi-square test finding for the use of Theme types $(\mathrm{df}=12)$ indicates significant differences between the seven dentistry subdisciplines at $\mathrm{p}<.05$ ( $\mathrm{p}$-value $=0.0294$ ), whereas there were no significant differences in the use of thematic markedness between the seven subdisciplines since the p-value was larger than .05 ( $\mathrm{p}$-value $=0.0762, \mathrm{df}=11.419)$.

\section{Topical Theme}

The results showed that topical Theme was the most frequently used Theme type in the RA abstracts of all seven dentistry subdisciplines (Table 3). Between $85.46 \%$ and $90.55 \%$ of all the Theme types occurring in the dentistry RA abstracts were topical Themes. This indicates the authors' awareness that maintaining the same entity (or topic) as the Theme of more than one clause develops a topic-focused text. This finding is in line with many studies (Alotaibi, 2020; Ebrahimi, 2016; Ebrahimi \& Khedri, 2011; Ghadessy, 1999; Leong, 2016). For example, Leong (2016) investigated $200 \mathrm{RA}$ abstracts from science and humanities disciplines and found that topical Themes were used more in scientific abstracts. As stated in Section 2, this finding is not surprising since the unmarked Theme is the typical way of starting the message of a clause.

Another interesting finding is the minimal occurrence of what I call a stand-alone (or one-word) topical Theme (1.31-5.32) in three of the seven dentistry subdisciplines (Table 4). The authors preferred to highlight the topical Theme by using the heading "Objectives." These instances mostly occurred at the beginning of the RA abstracts where the authors presented the 'background/objectives' of their study without repeating the whole Theme: "Objectives [Theme] To compare Oral health-related quality of life (OHRQoL) among 9-year-old children with excessive overjet (EO) to children with unilateral posterior crossbite (UPC) and children with normal occlusion (NO)” [Rheme] // (European Journal of Orthodontics, 2019). 
Table 4

The frequency and percentage of complete and stand-alone topical Themes in the dentistry RA abstracts

\begin{tabular}{lccccccc} 
& \multicolumn{1}{c}{ Subdiscipline } & \multicolumn{2}{c}{$\begin{array}{c}\text { Complete } \\
\text { Theme }\end{array}$} & \multicolumn{2}{c}{$\begin{array}{c}\text { One-word } \\
\text { Theme }\end{array}$} & \multicolumn{2}{c}{$\begin{array}{c}\text { Topical } \\
\text { Themes }\end{array}$} \\
\cline { 2 - 7 } & Freq & \% & Freq & \% & Freq & \% \\
\hline Oral Sciences & 194 & 100 & 0 & 0.00 & 194 & 100 \\
Periodontics & 132 & 100 & 0 & 0.00 & 132 & 100 & 100 \\
Endodontics & 230 & 100 & 0 & 0.00 & 230 & 100 \\
Operative Dentistry & 226 & 98.69 & 3 & 1.31 & 229 & 89.11 \\
Prosthodontics & 231 & 95.46 & 11 & 4.54 & 242 & 87.68 \\
Oral \& Maxillofacial Surgery & 176 & 100 & 0 & 0.00 & 176 & 100 \\
Orthodontics & 249 & 94.68 & 14 & 5.32 & 263 & 93.59 \\
\hline
\end{tabular}

The required word limit is maintained in the dentistry RA abstract through the use of the stand-alone topical Theme "Objectives" that replaced the phrase "the objectives of the present study." As Tullu (2019, p. S14) states, since "abstracts are the only sections of the research paper that are often freely available to the readers on the journal websites," they need to be "simple, direct, specific, functional, clear, unbiased, honest, concise, precise, self-sufficient, complete, comprehensive, scholarly, balanced, and should not be misleading."

All the authors employed passive voice in their RA abstracts (Table 5) since the use of this construction is a characteristic feature of medical discourse (Amdur, Kirwan, \& Morris, 2010). Amdur, Kirwan, and Morris (2010, p. 102) state that medical writers employ passive constructions for five reasons: "to reflect objectivity, to avoid first-person pronouns, to appear scholarly and sophisticated, to avoid responsibility, and to conform to the established writing style." Writers employed passive constructions to background their role as agents (or doers) of the action. The topical Themes in Table 5 are conflated with the subject although they are the object at the syntactic level. For example, although the clause "Demineralized dentin beams" has the participant role of Goal rather than the Actor, it is the subject at the semantic level, whereas it is the object at the syntactic level.

Table 5

Instances of topical Themes in the dentistry RA abstracts

\begin{tabular}{|c|c|c|c|}
\hline Subdiscipline & $\begin{array}{l}\text { Textual } \\
\text { Theme }\end{array}$ & $\begin{array}{l}\text { Topical } \\
\text { Theme }\end{array}$ & Rheme \\
\hline Oral Sciences & & Demineralized dentin beams & were divided into groups ( $\mathrm{n}=10$ in each group) // \\
\hline \multirow{3}{*}{ Orthodontics } & and - & & incubated in artificial saliva (AS, control) ...// \\
\hline & & The study & would be strengthened \\
\hline & if & a longitudinal design & had been performed. // \\
\hline Prosthodontics & & CATIA 3D evaluation software & was used to assess the digital STL files ...// \\
\hline Operative Dentistry & & One hundred sixty-five NCCLs & were selected and randomly assigned to three groups. // \\
\hline $\begin{array}{l}\text { Oral \& Maxillofacial } \\
\text { Surgery }\end{array}$ & & $\begin{array}{l}\text { Patients who had palliative } \\
\text { procedures }\end{array}$ & were excluded. // \\
\hline
\end{tabular}

One of the authors in the Oral Sciences subdiscipline employed an elliptical topical Theme by using the structural conjunct 'and.'

Halliday (2014, p. 87) argues that "all deictic elements are characteristically thematic." A closer look at the elements selected as topical Themes in the dentistry RA abstracts reveals the occurrence of clause-initial deictic determiners (or demonstratives) 'this/these' in the subdisciplines periodontics, restorative dentistry, oral sciences, and endodontics (Frequency, $\mathrm{f},=11-17)$ ), whereas the frequency of occurrence of initial deictic determiners in the other subdisciplines ranged 3-8 (Table 6). 
Table 6

Examples of initial deictic determiner "this" as topical Theme $e^{4}$

\begin{tabular}{ll}
\hline \multicolumn{1}{c}{ Topical Theme } & Rheme \\
\hline “This recognition & leads to a significant increase in bacteria phagocytosis.” // (Journal of Endodontics, 2019) \\
“This study & $\begin{array}{l}\text { aimed to evaluate the effect of different interface designs on the loadbearing capacity of bilayered } \\
\text { composite structures (BLS).” // (European Journal of Oral Sciences, 2019) } \\
\text { “This case series }\end{array}$ \\
& aimed to clinically and histologically evaluate porcine-derived membrane ...”. // (International \\
& Journal of Periodontics \& Restorative Dentistry, 2019) \\
\hline
\end{tabular}

These deictic elements are the most commonly employed discourse deixis in RAs as they contribute to cohesion and coherence of a text. Most of the instances of the demonstrative (or deictic determiner) "this" co-occurred with the Themes "study," "case," "findings," and "results" when presenting the aims, as in "This retrospective cohort study [Theme] aimed to observe ... [Rheme]," "This case series [Theme] aimed to ... [Rheme]" and "In this observational series, [Theme] three patients ... [Rheme]." Other deictic elements that occurred in the dentistry subdisciplines included the deictic relatives "that," "which," and "who," particularly in the dentistry subdisciplines of orthodontics, prosthodontics, and oral and maxillofacial surgery ( $\mathrm{f}=18-49)$, whereas its occurrence in the other subdisciplines ranged 6-8.

Another topical Theme observed in the dentistry RA abstracts is the first-person plural pronouns 'we/our', which were employed in five out of the seven dentistry subdisciplines. The use of this form indicates an authorial stance and increased author visibility (Ebrahimi \& Chan, 2015; Ebrahimi, Chan, \& Ain, 2014; Leong et al., 2018; McKenna, 1997). Whereas this form occurred frequently in the oral and maxillofacial surgery subdiscipline (47 instances), it rarely occurred in the other four subdisciplines (2-8 instances). This suggests oral and maxillofacial surgery scholars' preference to exhibit greater visibility than their counterparts in the other dentistry subdisciplines. This could also be attributed to the peculiar epistemologies of oral and maxillofacial surgery that differentiate it from the other subdisciplines. Researchers argue that a further function of thematized "we" is that it enables the authors to emphasize the novelty of their proposed work (Ebrahimi \& Chan, 2015; Martínez, 2003), which seems to be the case in the following excerpts.

(1) "We therefore suggest that it is used when discussing surgical outcomes, taking consent from newly-diagnosed patients, and when calculating the costs of head and neck oncological surgery." " We evaluated the degree of autophagy and cytoplasmic HMGB1 in radioresistant oral squamous cell carcinoma."/ "In this prospective study, [Theme] we meticulously searched for more examples using both formalin-fixed cadavers and neck dissections. [Rheme]"/ "We retrospectively reviewed the impact of repair of cleft lip on marriage in adult patients in our institution by questioning a group of patients treated from July 2009-June 2017.” (British Journal of Oral \& Maxillofacial Surgery, 2019)

The use of the first-person plural pronoun "we" was more frequent than the possessive "our" in the other six subdisciplines. This contradicts Behnam, Mirzapour, and Mozaheb's (2014) study of Chemistry RAs, which showed that writers in hard sciences use the first-person plural possessive "our" more than "we" because they are trying to reduce the responsibility of their claim. The dental authors used the first-person plural pronoun "we" to show their contributions to their field of research. This result also refutes the claim that personal pronouns are very rarely employed in hard disciplines (Hyland, 2005) as quantitative research must be objectives and impersonal. Kuo (1999) states that writers use the exclusive "we" to express their role and contribution to their field of research. The frequent use of the first-person plural pronoun "we" converges with several studies of personal pronouns in linguistics (Molino, 2010), applied linguistics (Dobakhti \& Hassan, 2017), and computer science, electronic engineering, and physics (Kuo, 1999). For example, Dobakhti and Hassan (2017) investigated authorial presence in Applied Linguistics RAs and found that plural pronouns are more common in quantitative than qualitative RAs. These studies, however, attributed the use of first-person plural pronouns not only to multiple authorship (exclusive "we") but also to involve the author and the reader (inclusive "we") in the argument. The RA abstracts of the periodontics, restorative dentistry, and prosthodontics subdisciplines lacked instances of the first-person plural pronoun

\footnotetext{
${ }_{4}$ Double slashed lines indicate the end of a T-unit.
} 
"we" since members of this discourse community seem to have preferred employing the traditional conventions of academic writing by retaining an objective stance through the use of passive constructions so that their abstracts appear more professional. As all the RA abstracts were written by multiple authors, none of the seven dentistry subdisciplines included instances of first-person singular pronouns. The use of first-person plural pronouns in five out of the seven dentistry subdisciplines reflects the collaborative nature of these subdisciplines where multiple authors are involved (or foregrounded as agents). It also indicates the authors' confidence in the propositions or the claims they are making.

\section{Textual Theme}

The results showed that textual Theme was the second most frequently used Theme type in the RA abstracts of all the seven dentistry subdisciplines (Table 3). The frequency of this Theme type ranged from $5.34 \%$ to $14.54 \% \mathrm{~A}$ textual Theme is employed to set grammatical and/or semantic relations within a clause using conjunctions (e.g. so, but, or), while logico-semantic relationships between a clause and the preceding text were established using conjunctive adjuncts of addition, apposition, and other semantic relations (e.g. however, while, on the other hand). Over half of the instances of the textual elements were 'and' followed by 'however.' Conjunctive adjuncts are employed in RA abstracts to explicitly advance arguments and highlight the importance of the study. This finding is in line with Alotaibi's (2020) study of Theme in computer science, which indicated the heavy use of conjunctive adjuncts. Table 7 shows instances of the authors' ways of realizing causal (therefore, consequently), adversative (however), and additive (additionally, moreover) meanings through conjunctive adjuncts.

\section{Table 7}

Examples of textual Theme in the dentistry RA abstracts

\begin{tabular}{|c|c|c|c|c|}
\hline Subdiscipline & Textual Theme & Interpersonal & Topical Theme & Rheme \\
\hline Oral Sciences & However, & & high concentrations of tHA & $\begin{array}{l}\text { stimulate production of reactive } \\
\text { oxygen species (ROS), resulting in cell } \\
\text { injury and apoptosis.// }\end{array}$ \\
\hline Periodontics & However, & very little & evidence of long-term results & is available. // \\
\hline Orthodontics & Therefore, & & in regular orthodontic cases, & $\begin{array}{l}\text { the choice between anchoring devices } \\
\text { may rely on other factors, such as } \\
\text { costs, patient comfort, personal } \\
\text { preferences, familiarity with the } \\
\text { device, and insertion procedures. // }\end{array}$ \\
\hline Endodontics & Additionally, & & in the CBCT images, & $\begin{array}{l}\text { the number of apical foramina was } \\
\text { also evaluated.// }\end{array}$ \\
\hline Operative Dentistry & Moreover, & & $\begin{array}{l}\text { the } 1.5 \% \text { hydrogen peroxide- or } \\
\text { essential oil-based mouth rinses }\end{array}$ & $\begin{array}{l}\text { affected the bleached enamel } \\
\text { properties, promoting an alteration in } \\
\text { morphologic surface and mineral loss } \\
\text { in depth.// }\end{array}$ \\
\hline
\end{tabular}

Similar conclusions were drawn in previous research showing that retrospective cohesive devices tend to occur in argumentative RA sections to persuade readers of the validity of claims (Gosden, 1992; Jalilifar, 2010).

\section{Interpersonal Theme}

The use of interpersonal Theme in dentistry RA abstracts was negligible. This finding converges with several studies of Theme in RA abstracts (e.g. Alotaibi, 2020; Ebrahimi, 2016; Ghadessy, 1999). The low percentage of the interpersonal Theme type is in line with what would be expected in objective, non-evaluative scientific RA discourse (Gray \& Biber, 2012; Hyland, 2005). Except for the orthodontics subdiscipline, the other six dentistry RA abstracts included instances of impersonal projections that expanded the meaning potential in a clause, as they created a logical relation between Theme-Rheme (e.g., 'show,' ‘suggest,' and 'indicate'): 'Our results show that ...." These projections yield a clear and coherent line of argument. Halliday (2004, p. 155) argues that "as scientific discourse has come to be depersonalized, during the past hundred years or so, impersonal projections have tended to be increasingly hedged around."

Rather than using interpersonal Themes, the dentistry scholars employed modality (e.g. should, must), as in "Clasps composed of zirconia should improve aesthetics without inducing the risk of metal allergy //" (European 
Journal of Oral Sciences, 2019). Stotesbury (2003) believed that while the humanities and social sciences employ more evaluative attributes (e.g. Interpersonal Themes), natural sciences more often resort to modality to express authorial stance.

\section{Marked \& Unmarked Themes}

The findings revealed that unmarked Themes are far more prevalent than marked Themes in the RA abstracts of all the seven dentistry subdisciplines (Table 3). The distribution of thematic markedness was almost equal across the seven dentistry subdisciplines, as evidenced by the chi-square test finding that showed no significant differences in the use of thematic markedness across the seven subdisciplines ( $p$-value $=0.0762, d f=12 \& 6$ ). The frequency of unmarked Themes ranged between $85.15 \%$ and $92.78 \%$, whereas that of marked ranged $7.22 \%-14.85 \%$ (Table 3). The high frequency of unmarked Theme indicates the authors' preference for maintaining the same topic rather than shifting focus through the frequent use of marked Themes (e.g., "The remake rate for crowns [Unmarked Theme] was 3.8\% [Rheme]" (Journal of Prosthodontics- Implant Esthetic \& Reconstructive Dentistry, 2019). The authors' preference for employing the typical(or usual) way of starting the message in a clause (i.e. using the unmarked Theme) is expected since it saves text space. The frequent use of unmarked Themes could be attributed to the relatively compact nature of the RA abstract. This finding is in line with the majority of studies (e.g. Alotaibi, 2020; Ebrahimi, 2016; Ebrahimi \& Khedri, 2011; Ghadessy, 1999; He \& Tian, 2018; Leong, 2016) which found that unmarked Themes outnumbered the marked Themes. For example, Ebrahimi and Khedri (2011) found that unmarked Themes were over-used in RA abstracts of both Chemical Engineering and Applied Linguistics.

Marked Themes are employed in the prosthodontics subdiscipline to validate claims and to provide information related to time or space, as shown in Excerpts 2-5 below.

(1) "According to the results of this study, [Marked Theme] the digital implant impression technique had the least accuracy." [Rheme] //

(2) "After that, [Marked Theme] the splinted assemblies were attached to implant analogs (DANSE) ..." [Rheme] //

(3) "After bonding, [Marked Theme] the shear bond strength (SBS) of the ceramic to dentin was measured." [Rheme] //

(4) "In the CRC group, [Marked Theme] 75\% of the failures were of the adhesive type, compared with 66.7\% and $83.3 \%$ in the LRC and LGC groups, respectively." [Rheme] // (Journal of Prosthodontics, 2019)

The adverbial group and the prepositional phrases (or circumstantial adjuncts) function as Theme as they can be moved into Rheme position (backgrounded); both the Theme and Rheme are called agnate clauses since they are reversible. The circumstances in the above excerpts conflate with the Subject (or take its position) to make texts more elaborate. Fronting the circumstantial elements allows authors to place the study within a wider context and thereby motivate the study. Davies (1989) states that a marked Theme is mostly employed in scientific RAs to validate some evidence (e.g. according to our findings), a writer's viewpoint (Surprisingly), and time/space (in brief, in figure x). Alyousef (2020) argues that a Theme is emphasized through intonation when it is moved into the Rheme position and replaced with adverbial or prepositional phrases.

The first part of this section examined within-clause thematic choices. What follows is the global thematic analysis of the dentistry RA abstracts to reveal the authors' preferred ways of sequencing information across the clause.

\section{Global Organization}

A combination of linear and constant Theme patterns constituted over $90 \%$ of the TP patterns in the seven dentistry subdisciplines (Table 3). This finding is in line with the majority of studies on RA abstracts in other disciplines (e.g. Lorés, 2004; Nwogu \& Bloor, 1991). The chi-square test finding for the use of TP patterns indicated no significant differences across the seven dentistry subdisciplines ( $\mathrm{p}$-value $=0.5777, \mathrm{df}=10.436$ ).

\section{Linear TP pattern}

The linear (or zig-zag) TP pattern was the most dominant pattern in five out of the seven subdisciplines, as the prosthodontics and the orthodontics RA abstracts had slightly more instances of constant TP patterns than linear. The occurrence of the linear TP pattern in the seven subdisciplines comprised $45.46 \%-64.71 \%$ of all the 
TP patterns. The dominance of this pattern corresponds with studies of RA abstracts in sciences and humanities (Leong, 2016) and applied linguistics (Ebrahimi, 2016; Lorés, 2004). The high frequency of this pattern can be explained by the fact that this pattern contributes to a hierarchically structured cohesive text when information in the Rheme position is linked and developed in the subsequent Theme, thereby creating a clear and coherent line of argument that acts as a lead for readers. As Halliday (1993, p. 131) states, scientific texts tend to develop a linear "chain of reasoning (ultimately based on experiments) in which each step led on to the next." The skillful employment of this pattern is illustrated in Table 8.

Table 8

Examples of linear TP pattern in the seven dentistry RA abstracts

\begin{tabular}{|c|c|c|}
\hline Subdiscipline & Theme & Rheme \\
\hline \multirow[t]{2}{*}{ Oral Sciences } & $\begin{array}{l}\text { The marginal signal near } 4 \mathrm{q} 31 \text { detected in } \\
\text { previous genome-wide association studies }\end{array}$ & $\begin{array}{l}\text { might be caused by an interaction between the IRF6 } \\
\text { and GLRB genes. }\end{array}$ \\
\hline & This interaction & $\begin{array}{l}\text { needs to be further validated by experimentation in } \\
\text { follow-up studies. }\end{array}$ \\
\hline \multirow[t]{2}{*}{$\begin{array}{l}\text { Periodontics \& Restorative } \\
\text { Dentistry }\end{array}$} & $\begin{array}{l}\text { Microcomputed tomography and histologic } \\
\text { and histomorphometric analyses }\end{array}$ & were performed to determine bone density. \\
\hline & Bone density & $\begin{array}{l}\text { increased significantly over time }(\mathrm{P}<.001) \text {, with } \\
\text { stabilization between } 12 \text { and } 24 \text { weeks }(\mathrm{P}=1.000) . / /\end{array}$ \\
\hline \multirow[t]{2}{*}{ Endodontics } & Our aim & was to determine their relevance to infected pulp \\
\hline & Diseased pulp tissue & $\begin{array}{l}\text { was stained for the presence of extracellular DNA } \\
\text { and elastase to detect the presence of NETs.// }\end{array}$ \\
\hline \multirow[t]{2}{*}{ Prosthodontics } & The sample & $\begin{array}{l}\text { included } 134 \text { subjects-students of the University } \\
\text { of Rijeka, Croatia ( } 65 \% \text { female) aged } 19 \text { to } 28 \text { years } \\
\text { (median 21).// }\end{array}$ \\
\hline & All subjects & $\begin{array}{l}\text { had six intact maxillary anterior teeth without } \\
\text { restorations or severe malocclusions and healthy } \\
\text { gingiva with no signs of inflammation.// }\end{array}$ \\
\hline \multirow{2}{*}{$\begin{array}{l}\text { Oral \& Maxillofacial } \\
\text { Surgery }\end{array}$} & Between December 2015 and June 201844 & patients had skull SPECT (15 male and 29 female \\
\hline & They & were having bone scans ...// \\
\hline \multirow[t]{2}{*}{ Orthodontics } & Objectives & $\begin{array}{l}\text { To investigate the changes in oral health-related } \\
\text { quality of life (OHRQoL) before, during, and after } \\
\text { orthodontic treatment,...// }\end{array}$ \\
\hline & $\begin{array}{l}\text { Materials and methods } \\
\text { OHRQoL questionnaires }\end{array}$ & $\begin{array}{l}\text { were used in an ongoing observational prospective } \\
\text { cohort study at baseline (T0), } 1 \text { year after start (T1), } \\
\text { and } 1 \text { month after the end of active orthodontic } \\
\text { treatment (T2).// }\end{array}$ \\
\hline \multirow[t]{2}{*}{ Operative Dentistry } & At T3, & group CU exhibited the lowest $\Delta \mathrm{E}$ values $(\mathrm{p}=0.008) . / /$ \\
\hline & The $\Delta \mathrm{E}$ values & increased from $\mathrm{T} 4$ to $\mathrm{T} 5$ in the $\mathrm{CW}$ and CU groups, // \\
\hline
\end{tabular}

Each bolded Theme in Table 8 is derived from the Rheme in the previous clause, giving a strong sense of topic continuity and in turn sustaining the argument being made. The clause-initial deictic determiner 'this' in one of the oral sciences RA abstracts refers back to the clause "an interaction between the IRF6 and GLRB genes." The author uses this element instead of repeating the whole clause to save text space. Similarly, the author in the prosthodontics subdiscipline employs the Theme (head noun) "All subjects" to refer to back to the clause "134 subjects-students of the University of Rijeka, Croatia (65\% female) aged 19 to 28 years (median 21).” Structuraltopical Themes, such as 'that' in relative clauses and 'which / who,' conflate with the Subject to produce cohesive and elaborated discourse through the use of linear TP pattern, as in "Polydopamine-templated hydroxyapatite (tHA) [Theme] is a type of nano-biomaterial [Rheme] that [Theme] can promote osteogenesis in bone tissue engineering. [Rheme]//" (Oral Sciences Journal, 2019). It should be noted that the demonstratives 'this', 'these' and 'that' seem most often to be used anaphorically referring back to a proposition in the Rheme position (See also Table 6). This pattern aids scholars in producing a characteristically coherent argumentative RA abstract, as they have to convince their readers of the relevance of their proposed work (Swales, 2004). 


\section{HESHAM SULEIMAN ALYOUSEF}

\section{Constant TP Progression}

The second most common TP pattern in the dentistry RA abstracts was the constant pattern, comprising $30.77 \%-49.12 \%$ of all the TP patterns the authors employed as one of the methods to develop information. While all seven dentistry subdisciplines recognized the usefulness of linking clauses by repeating the Theme of a previous clause, the qualitative analysis indicated that they skillfully used it for slightly different purposes. There was no quantitative difference in the use of the constant TP pattern across the seven dentistry subdisciplines; the qualitative analysis, however, revealed a difference in the functions that underlie the use of this pattern (Table 9).

\section{Table 9}

Examples of constant TP pattern in the dentistry RA abstracts

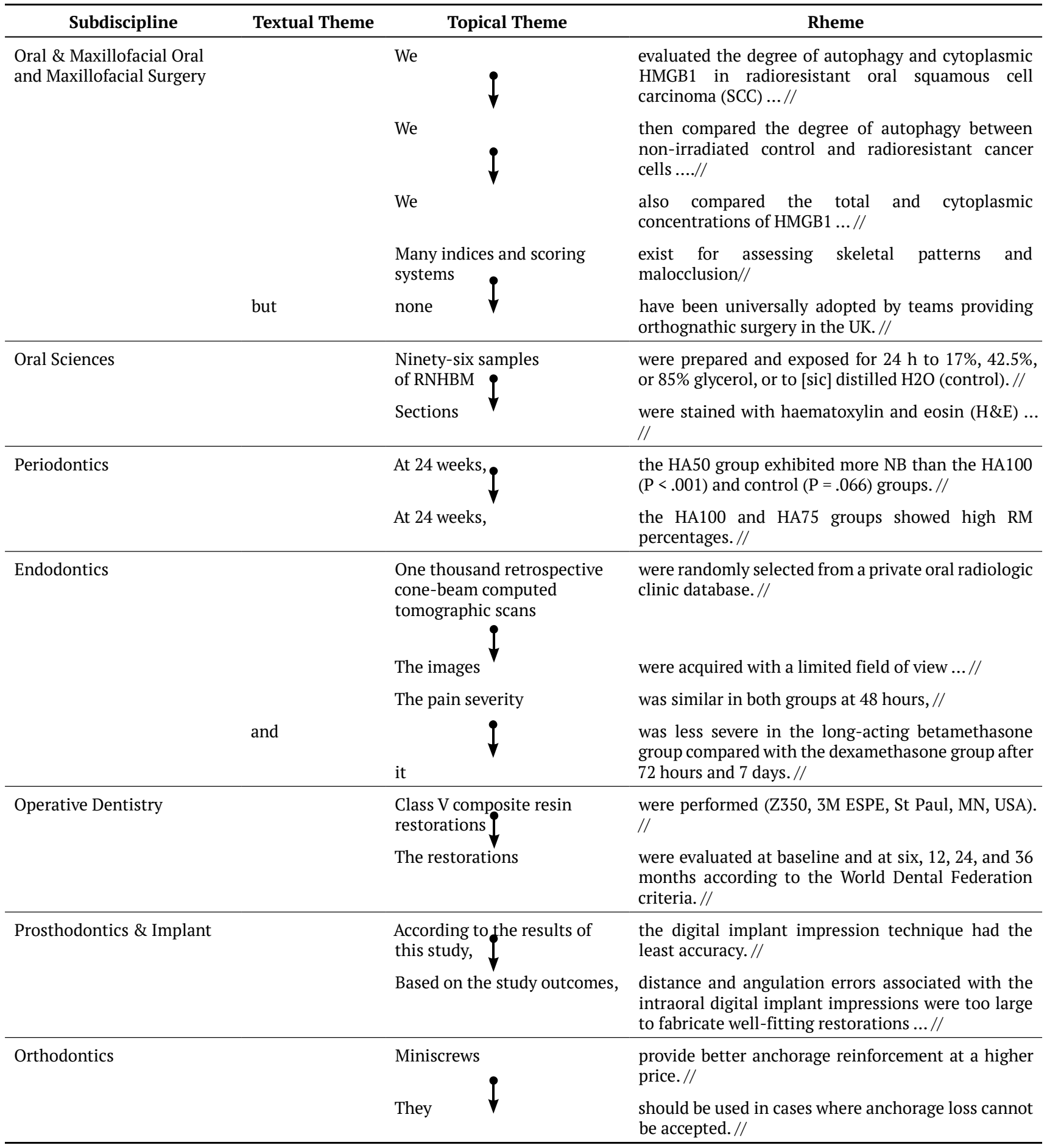


The thematic element "we" (referring to the authors) was successively reiterated across several clauses to recursively present the aims and the methods (Alyousef, in press). The reiterated clause "ninety-six samples of RNHBM (reconstructed normal human buccal mucosa)" in the oral sciences subdiscipline is elided (or omitted) in the following clause and replaced by the word "sections" to refer to the presupposed clause "sections of the RNHBM samples." In the oral and maxillofacial surgery RA abstracts, the word "none" was employed instead of reiterating the clause "Many indices and scoring systems." The use of this complex pattern demonstrates the author's advanced writing skills where each aim is followed by the procedure which keeps the reader focused. Rather than repeating the same Theme "cone-beam computed tomographic scans," one of the authors in the endodontics subdiscipline uses the synonym "images." Similarly, one of the authors in the prosthodontics subdiscipline used the synonym 'outcomes' in "the study outcomes" instead of reiterating the same phrase "the results of this study." Finally, the classifiers (or the words) "Class V composite resin" accompanying the head noun "restorations" in the operative dentistry RA abstract was deleted in the following clause and replaced with "the restorations" to avoid redundancy. The identified functions of this pattern offer authors a strategy to give additional information about a topic closely related to their work. The dental authors demonstrated their advanced writing skills by not only reiterating Theme but also using various writing strategies that cope with word limit constraints, such as omitting the classifiers (or words) accompanying the head noun, the use of synonyms, and the pronouns "it" and "none."

\section{Split Rheme TP Pattern}

The split Rheme pattern occurred the least in all seven subdisciplines, comprising $0.00 \%-6.06 \%$ of all the TP patterns. This finding, however, was expected due to the concise nature of an RA abstract, which requires an author to shift from one proposition to another. The split TP pattern unfolds across many clauses because it carries several pieces of information revolving around one major topic, with each piece taking a thematic position in a separate consequent clause, forming a cluster of topically related clauses. Although there was a quantitative difference in the use of the split pattern across the seven dentistry subdisciplines, the qualitative analysis found a similarity in the functions of this pattern (Table 10).

\section{Table 10}

Examples of split Rheme pattern in the dentistry RA abstracts

\begin{tabular}{|c|c|c|}
\hline Subdiscipline & Theme & Rheme \\
\hline \multirow[t]{4}{*}{ Oral Sciences } & Wistar albino rats & $\begin{array}{l}\text { were randomized into four groups: control; ALA; AP; and } \\
\text { ALA + AP. // }\end{array}$ \\
\hline & Rats of the control and ALA groups & were not endodontically treated, // \\
\hline & but saline and ALA (100 mg kg_1) & were administered. // \\
\hline & $\begin{array}{l}\text { In rats of the } \mathrm{AP} \text { and } \mathrm{ALA}+\mathrm{AP} \\
\text { groups, }\end{array}$ & $\begin{array}{l}\text { the pulp chambers of mandibular first molar teeth were } \\
\text { exposed and left open for } 30 \mathrm{~d} \\
\text { to induce AP.// }\end{array}$ \\
\hline \multirow[t]{3}{*}{ Endodontics } & $\begin{array}{l}\text { Methods: In this double-blind } \\
\text { randomized clinical trial, }\end{array}$ & $\begin{array}{l}242 \text { healthy patients with irreversible pulpitis undergoing } \\
\text { 1-visit endodontic treatment were included.// }\end{array}$ \\
\hline & Forty-five patients & were lost during the follow-up, // \\
\hline & and the remaining 197 patients & $\begin{array}{l}\text { were followed for } 7 \text { days ( } 67 \text { patients in the placebo group, } \\
66 \text { in the long-acting betamethasone group, and } 64 \text { in the } \\
\text { dexamethasone group).// }\end{array}$ \\
\hline \multirow[t]{3}{*}{ Operative Dentistry } & Participants in each group & were further divided randomly into two subgroups. // \\
\hline & In subgroups $\mathrm{A} 1, \mathrm{~B} 1$, and $\mathrm{C} 1$ & an intensive preventive protocol was applied, // \\
\hline & while in subgroups A2, B2, and C2, & the protocol consisted only of instructions in oral hygiene. // \\
\hline
\end{tabular}

The authors used a split Rheme pattern to link clauses containing a list of points (or aspects) such as the four groups "control; ALA; AP; and ALA + AP" in the oral sciences subdiscipline.

The skillful use of this pattern establishes cohesion in the text as the elements in the Rheme signal connections with the successive Themes by highlighting the subsequent propositional content. The split Rheme pattern thus functions prospectively as a guide to signal the information coming next. The lack of significant intradisciplinary differences in the use of TP patterns across the seven dentistry subdisciplines could be attributed to the conventional stylistic practice in the dentistry discipline that requires the non-random use of 


\section{HESHAM SULEIMAN ALYOUSEF}

constant and linear TP patterns. This finding corresponds with Lorés's (2004) and Nwogu and Bloor's (1991) studies which indicated that RA abstracts tend to combine these two patterns. Table 11 summarizes the significant intradisciplinary similarities and differences in the use of thematic choices and TP patterns in the seven subdisciplines.

\section{Table 11}

Similarities and differences in the use of thematic choices and TP patterns in the seven subdisciplines Linguistic Aspect

Function \& notes

\section{Example}

Topical Theme (most frequently used - Developing a topic-focused text

Theme type in all the seven dentistry - Most of the instances of the demonstrative subdisciplines). (or deictic determiner) "this" co-occurred outcome of Resilon... [Rheme]" (Journal of with the Themes "study," "case," "findings," Endodontics, 2019). and "results" when presenting the aims.

- Use of first-person plural pronouns "we/our" as Topical Themes to indicate an authorial stance and increased author visibility (highly employed in the Oral and Maxillofacial Surgery subdiscipline).

Textual Theme (second most frequently - Develops grammatical and logico-semantic "However, [Textual Theme] high concentrations used Theme type in all the seven links within and beyond a clause. of tHA [Topical Theme] stimulate production of dentistry subdisciplines although - Over half of the instances of the used textual its occurrence in the Orthodontics elements were 'and' followed by 'however.' subdiscipline was the least).

- Conjunctive adjuncts explicitly advance arguments and highlight the importance of the study.

Interpersonal Theme (minimally - Expresses a writer's opinion. employed in four subdisciplines- e.g. - Modality expresses an author's authorial only, most- but all the seven dentistry stance.

subdisciplines employed modality, e.g.

should, must).

Unmarked Themes (far more prevalent - Maintaining the same topic. reactive oxygen species (ROS), resulting in cell injury and apoptosis. [Rheme] //" (European Journal of Oral Sciences, 2019).

than the marked Themes in all the - Saving text space through the use of seven dentistry subdisciplines, $85.15 \%$ - Unmarked Themes. 92.78\%).

"Clasps composed of zirconia should improve aesthetics without inducing the risk of metal allergy" // (European Journal of Oral Sciences, 2019).

"We [Unmarked Theme] used novel analytical approaches to identify inflammatory response patterns to plaque accumulation in experimental gingivitis studies in humans. [Rheme]" (European Journal of Oral Sciences, 2019).

Marked Theme (minimally employed - To validate claims (e.g. according to our "According to the results of this study, [Marked in all subdisciplines, $7.22 \%-14.85 \%$ ). findings),

Theme] the digital implant impression - To provide information related to time and space. technique had the least accuracy [Rheme]." //

"After that, [Marked Theme] the splinted assemblies were attached ... [Rheme]" // (Journal of Prosthodontics, 2019).

Linear (or zig-zag) TP pattern (most - Creates a clear and coherent line of argument dominant pattern in all subdisciplines, that acts as a lead for readers.

$45.46 \%-64.71 \%)$

- Saving text space through the use of head nouns and demonstratives 'this', 'these', and 'that' to refer back to a proposition in Rheme position.

"In the entire sample, [Theme] 115 (51.57\%) patients were females and $108(48.43 \%)$ were males [Rheme]. They [Theme] ranged in age from 28 to 81 years old. [Rheme]" (Journal of Prosthodontics- Implant Esthetic \& Reconstructive Dentistry, 2019).

Constant TP pattern (second most - Maintain readers' focus on the topic.

common pattern in all subdisciplines, - Save text space through the use of the 30.77\%-49.12\%; highest were pronouns "it" and "none" as well as omitting Prosthodontics $49.12 \%$, Orthodontics the words accompanying the head noun.

"Many indices and scoring systems [Theme] exist for assessing skeletal patterns and malocclusion [Rheme]// but none [Theme] have been universally adopted by teams providing $48.48 \%$, and Endodontics $48.39 \%$ )

- The use of synonyms (results/ outcomes, tomographic scans/images) to avoid repetition and make the text more cohesive.

Split Rheme pattern (minimally used - Signal information coming in subsequent by six subdisciplines due to word limit clauses, thereby forming a cohesive text.

constraints, only 1-3 instances in each - Several pieces of information (or ideas/ subdiscipline, except for Periodontics, aspects) revolving around one major topic $\mathrm{n}=0$ ). are introduced in Rheme position, usually at the beginning of a paragraph, and then each piece takes a thematic position in a separate consequent clause. orthognathic surgery in the UK [Rheme]"// (British Journal of Oral \& Maxillofacial Surgery, 2019).

"Participants in each group [Theme] were further divided randomly into two subgroups. [Rheme]// In subgroups A1, B1, and C1, [Theme 1] an intensive preventive protocol was applied, [Rheme] // while in subgroups A2, B2, and $\mathrm{C} 2$, [Theme 2] the protocol consisted only of instructions in oral hygiene [Rheme]"// (Operative Dentistry, 2019). 


\section{Conclusion}

Several studies have conducted interdisciplinary investigations on variations and similarities in the thematic organization of RA abstracts across a range of disciplines; however, similar investigations of RA abstracts of dentistry subdisciplines are lacking. This research paper is significant as it is the first to investigate the local and global organization of Theme in RA abstracts of seven dentistry subdisciplines. The results highlighted quantitative and qualitative intradisciplinary similarities and differences. The qualitative results showed that even though there were no significant interdisciplinary differences between the dentistry RA abstracts and the findings reported in the literature of other disciplines, various interesting linguistic features characterizing the subdisciplines were employed: elliptical topical Themes, one-word topical Themes (in three subdisciplines), passive constructions to reflect objectivity and professionalism, and clause-initial deictic demonstratives 'this/ these' (in three subdisciplines). Oral and maxillofacial surgery authors regularly used first-person pronouns to express their role and contributions to the field of research and indicate increased author visibility.

The study has practical implications for novice dental researchers attempting to write an RA abstract as well as for tutors of English for Academic Purposes courses. One important implication of the results is that thematicity helps academic writers orient their writing at the text level rather than the sentence level through the skillful use of TP patterns. An awareness of the available thematic choices and TP patterns yields a well-structured cohesive and coherent message both within and across the clause. This in turn will facilitate smooth readability and could increase the readership of an abstract. Dental researchers need to consider the intradisciplinary significant similarities and differences in the use of Theme types as well as the key linguistic features when writing an RA abstract in one of the seven subdisciplines. Having observed these important aspects, the flow and organization of a dentistry RA abstract will be more effective and the chances of having a paper accepted in a high-ranking journal will increase.

Future studies could further investigate thematic choices and TP patterns in other sections of dentistry RAs to compare their findings with those in the present study. It is also recommended that future research investigate and compare interdisciplinary variations in the use of Theme and TP patterns across subfields of other disciplines.

\section{Acknowledgments}

The author is indebted to the two anonymous reviewers for their insightful and helpful comments. He is also grateful to the editor who read the manuscript and provided invaluable comments as well as the dentist who extracted the terms and the sentences that are incomprehensible to a layperson. The author wishes to express his gratitude to both the Deanship of Scientific Research at King Saud University and the Research Centre at the Faculty of Arts for funding the present study.

\section{References}

Ai, H., \& Lu, X. (2013). A corpus-based comparison of syntactic complexity in NNS and NS university students' writing. In A. Díaz-Negrillo, N. Ballier, \& P. Thompson (Eds.), Automatic treatment and analysis of learner corpus data (pp. 249-264). John Benjamins.

Alotaibi, H. S. (2020). The thematic structure in research article abstracts: Variations across disciplines. Cogent Arts \& Humanities, 7(1), 1756146. https://doi.org/10.1080/23311983.2020.1756146

Alyousef, H. S. (2020). A multimodal discourse analysis of English dentistry texts written by Saudi undergraduate students: A study of theme and information structure. Open Linguistics, 6, 267-283. https://doi.org/10.1515/ opli-2020-0103

Alyousef, H. S. (in press). A move-structure model for dentistry research article abstracts: A genre-based study of variations and similarities in seven dentistry subdisciplines. Discourse \& Interaction, 14(1).

Amdur, R. J., Kirwan, J., \& Morris, C. G. (2010). Use of the passive voice in medical journal articles. AMWA Journal: American Medical Writers Association Journal, 25(3), 98-104. https://doi.org/10.2302/kjm.2014-0009-RE

Behnam, B., Mirzapour, F., \& Mozaheb, M. A. (2014). Writer's presence in English native and non-native speaker research articles. Procedia-Social \& Behavioral Sciences, 98(6), 369-374. https://doi.org/10.1016/j. sbspro.2014.03.428 


\section{HESHAM SULEIMAN ALYOUSEF}

Daneš, F. (1974). Functional sentence perspective and the organization of the text. In F. Daneš (Ed.), Papers on functional sentence perspective (pp. 106-128). Academia.

Davies, F. (1989). Developing competence in academic discourse: The role of language awareness (ELU Working Paper No. 1). University of Liverpool.

Dobakhti, L., \& Hassan, N. (2017). A Corpus-based study of writer identity in qualitative and quantitative research articles. 3L: The Southeast Asian Journal of English Language Studies, 23(1), 1-14. http://doi. org/10.17576/3L-2017-2301-01

Ebrahimi, S. F. (2016). Theme types and patterns in research article abstracts: A cross disciplinary study. International Journal of English Language \& Translation Studies, 4(3), 104-115.

Ebrahimi, S. F., \& Chan, S. H. (2015). Research article abstracts in Applied Linguistics and Economics: Functional analysis of the grammatical subject. Australian Journal of Linguistics, 35(4), 381-397. https://doi.org/10.1080 /07268602.2015.1070660

Ebrahimi, S. F., Chan, S. H., \& Ain, N. A. (2014). Discourse functions of grammatical subject in results and discussion sections of research article across four disciplines. Journal of Writing Research, 6(2), 125-140. https://doi.org/10.17239/jowr-2014.06.02.2

Ebrahimi, S. F., \& Khedri, M. (2011). Thematicity in research article abstracts: A cross-disciplinary study. Educational Quest: An International Journal of Education and Applied Social Sciences, 2(3), 287-292.

Forey, G., \& Sampson, N. (2017). Textual metafunction and Theme: What's “it” about? In T. Bartlett \& G. O'Grady (Eds.), The Routledge handbook of systemic functional linguistics (pp. 131-145). Routledge.

Fries, P. (1995). Themes, methods of development, and texts. In R. Hasan \& P. Fries (Eds.), On subject and theme: A discourse functional perspective (pp. 317-360). John Benjamins.

Ghadessy, M. (1999). Thematic organization in academic article abstracts. Estudios ingleses de la universidad complutense, $7,141-161$.

Gosden, H. (1992). Discourse functions of marked theme in scientific research articles. English for Specific Purposes, 11(3), 207-224. https://doi.org/10.1016/S0889-4906(05)80010-9

Gray, B., \& Biber, D. (2012). Current conceptions of stance. In K. Hyland, \& C. S. Guinda (Eds.), Stance and voice in written academic genres (pp. 15-33). Palgrave Macmillan.

Halliday, M. A. K. (1993). The analysis of scientific texts in English and Chinese. In M. A. K. Halliday \& J. R. Martin (Eds.), Writing science: Literacy and discursive power (pp. 124-132). Falmer Press.

Halliday, M. A. K. (2004). The Language of Science. In J. Webster (Ed.), Collected works of M.A.K.Halliday (vol. 5, pp. 162-178). Continuum.

Halliday, M. A. K. (2014). Introduction to Functional Grammar. Revised by Christian M. I. M. Matthiessen (4th ed.). Taylor \& Francis.

Hasan, R., \& Fries, P. H. (1995). Reflections on subject and theme: An introduction. In R. Hasan \& P. H. Fries (Eds.), On subject and theme : A discourse functional perspective (pp. xiii-xlv). John Benjamins.

He, Y., \& Tian, J. (2018). A Comparative study of thematic progression in abstracts of scientific papers: A case study of science and science bulletin. International Journal of Arts and Commerce, 7(7), 1-7.

Hyland, K. (2005). Stance and engagement: A model of interaction in academic discourse. Discourse Studies, 7(2), 173-192. https://doi.org/10.1177/1461445605050365

Jalilifar, A. R. (2010). The status of theme in applied linguistics articles. Asian ESP Journal, 6(2), 7-39.

Kuo, C.-H. (1999). The use of personal pronouns: Role relationships in scientific journal articles. English for Specific Purposes, 18(2), 121-138. https://doi.org/10.1016/S0889-4906(97)00058-6

Leong, A. P. (2004). Theme and rheme: An alternative account (vol. 266). Peter Lang.

Leong, A. P. (2015). Topical themes and thematic progression: The "picture" of research articles. Text \& Talk, 35(3), 289-315. https://doi.org/10.1515/text-2015-0001

Leong, A. P. (2016). Thematic density of research-article abstracts: A systemic-functional account. WORD, 62(4), 209-227. https://doi.org/10.1080/00437956.2016.1248668

Leong, A. P., Toh, A. L. L., \& Chin, S. F. (2018). Examining structure in scientific research articles: A study of thematic progression and thematic density. Written Communication, 35(3), 286-314. https://doi. org/10.1177/0741088318767378

Lorés, R. (2004). On RA abstracts: From rhetorical structure to thematic organization. English for Specific Purposes, 23(3), 280-302. https://doi.org/10.1016/j.esp.2003.06.001

$\mathrm{Lu}, \mathrm{X}$. (2010). Automatic analysis of syntactic complexity in second language writing. International Journal of Corpus Linguistics, 15(4), 474-496. https://doi.org/10.1075/ijcl.15.4.02lu

$\mathrm{Lu}, \mathrm{X}$. (2011). A corpus-based evaluation of syntactic complexity measures as indices of college-level ESL writers' language development. TESOL Quarterly, 45(1), 36-62. https://doi.org/10.5054/tq.2011.240859 
Lu, X., \& Ai, H. (2015). Syntactic complexity in college-level English writing: Differences among writers with diverse L1 backgrounds. Journal of Second Language Writing, 29, 16-27. https://doi.org/10.1016/j. jslw.2015.06.003

Martínez, I. A. (2003). Aspects of theme in the method and discussion sections of biology journal articles in English. Journal of English for Academic Purposes, 2(2), 103-123. https://doi.org/10.1016/S1475-1585(03)00003-1

Mauranen, A. (1996). Discourse competence: Evidence from thematic development in native and non-native texts. In E. Ventola, \& A. Mauranen (Eds.), Academic Writing: Intercultural and textual issues (pp. 195-230). John Benjamins.

McCabe, A. M. (1999). Theme and thematic patterns in Spanish and English history texts [Unpublished doctoral dissertation]. University of Aston in Birmingham.

McGregor, W. (1992). The place of circumstantials in systemic-functional grammar. In A. Davies, \& L. Ravelli (Eds.), Advances in systemic linguistics: Recent theory and practice (pp. 136-149). Pinter.

McKenna, B. (1997). How engineers write: An empirical study of engineering report writing. Applied Linguistics, 18(2), 189-211. https://doi.org/10.1093/applin/18.2.189

Molino, A. (2010). Personal and impersonal authorial references: A contrastive study of English and Italian Linguistics research articles. Journal of English for Academic Purposes, 9(2), 86-101. https://doi.org/10.1016/j. jeap.2010.02.007

Nwogu, K. N., \& Bloor, T. (1991). Thematic progression in professional and popular medical texts. In E. Ventola (Ed.), Functional and systemic linguistics: Approaches and uses (vol. 55, pp. 369-384). Mouton de Gruyter.

Shamim, T. (2018). A working classification proposed for indices based on dental specialties in dental research. Mustansiriya Medical Journal, 17(2), 100-103. https://doi.org/10.4103/MJ.MJ_26_18

Stotesbury, H. (2003). Evaluation in research article abstracts in the narrative and hard sciences. Journal of English for Academic Purposes, 2(4), 327-341. https://doi.org/10.1016/S1475-1585(03)00049-3

Swales, J. (2004). Research genres: Explorations and applications. Cambridge University Press.

Thompson, G. (2004). Introducing functional grammar (2nd ed.). Arnold.

Tullu, M. S. (2019). Writing the title and abstract for a research paper: Being concise, precise, and meticulous is the key. Saudi Journal of Anesthesia, 13(1), 12-17. https://doi.org/10.4103/sja.SJA_685_18

Williams, I. A. (2009). Discourse style and theme-rheme progression in biomedical research article discussions: A corpus-based contrastive study of translational and non-translational Spanish. Languages in Contrast, 9(2), 225-266. https://doi.org/10.1075/lic.9.2.03wil

Young, R. (1995). Conversational styles in language proficiency interviews. Language Learning, 45(1), 3-42. https://doi.org/10.1111/j.1467-1770.1995.tb00961.x 